\title{
Divulgação científica e percepção pública de brasileiros(as) sobre ciência e tecnologia
}

\section{Science popularization and public perception of brazilians about science and technology}

Fernando Delabio (f_delabio@ hotmail.com) (Universidade Estadual de Maringá)

Débora Piai Cedran (depiai@yahoo.com.br) (Universidade Estadual de Maringá)

Lorraine Mori (loorrainemori@gmail.com) (Universidade Estadual de Maringá)

Neide Maria Michellan Kioranis (nmmkiouranis@gmail.com) (Universidade Estadual de Maringá)

Resumo: A divulgação científica tem ganhado especial atenção nas discussões a respeito da ciência e do ensino de ciências, muito devido à pesquisa realizada em 1987 sobre a percepção pública da ciência e da tecnologia, visando ações de divulgação científica. Os PCNEM e as PCN+ que trazem orientações sobre o uso dessa forma de comunicação no ensino são marcos na aproximação entre ensino e divulgação científica. Assim, incorporando-se à nossa cultura e aumentando a importância de analisar criticamente essas informações para entender melhor o que é e para que serve a divulgação científica, pois, sem alguns cuidados, pode ter impactos negativos. Buscamos investigar as relações entre as ideias ou percepções do público participante das pesquisas e suas próprias atitudes, divulgadas como resultados da pesquisa "Percepção Pública da Ciência e Tecnologia no Brasil". Os dados mostram uma população confiante nos benefícios da C\&T, contudo sem saber quais benefícios, nem apresentando o mesmo grau de confiança no solucionar problemas como fome e pobreza e, ainda, considerando das maiores responsáveis pelos problemas ambientais. Também contrastantes quanto à importância da participação em decisões sobre o rumo da ciência, enquanto mostra-se pouco interessada por ciência ou acredita que pessoas não são capazes de aprender ciência.

Palavras-chave: Concepções de Ciência; Divulgação Científica; Educação Científica.

Abstract: Science popularization has gained special attention in discussions about science and science teaching, largely due to the research carried out in 1987 on the public perception of science and technology, aiming at science popularization actions. PCNEM and PCN+ that provide guidance on the use of this form of communication in teaching are milestones in the approach between teaching and scientific communication. Thus, incorporating into our culture and increasing the importance of critically 
analyzing this information to better understand what science popularization is and what it is for, because without some care, it can have negative impacts. We seek to investigate the relationship between the ideas or perceptions of the public participating in the research and their own attitudes, disclosed as results of the research "Public Perception of Science and Technology in Brazil". The data shows a population confident in the benefits of S\&T, however without knowing which benefits, nor showing the same degree of confidence in solving problems such as hunger and poverty, and also considering those most responsible for environmental problems. Also contrasting as to the importance of participating in decisions about the direction of science, while showing little interest in science or believing that people are not able to learn science.

Keywords: Conceptions of Science; Science Popularization; Science Education.

\section{INTRODUÇÃO}

Nos últimos anos, a divulgação científica (DC) tem ganhado especial atenção nas discussões a respeito da ciência e do ensino de ciências. Isso se deve à pesquisa realizada no Brasil em 1987 sobre a percepção pública da ciência e da tecnologia, visando ações na área de DC, que apontou que cerca de $71 \%$ dos(as) brasileiros(as) se interessavam de alguma forma pela ciência (CUNHA, 2009). Outro fator relevante se deve às críticas realizadas por movimentos sociais a respeito de como a ciência tem se desenvolvido as quais impulsionaram a necessidade de conhecer a percepção e as atitudes das pessoas a seu respeito, além da perspectiva Ciência, Tecnologia e Sociedade (CTS) que coloca em evidência uma noção de cidadania científica que necessita de compreensão de aspectos sociais da ciência (SIMON, 2009).

Assim, podemos observar que a importância da divulgação da ciência vai tomando contornos sociais maiores a partir de informações como o crescimento da quantidade de revistas especializadas no país (Ciência e Cultura - 1941, Ciência Hoje 1982, Superinteressante - 1987, Globo Ciência/Galileu - 1991, Pesquisa FAPESP 1995, National Geographic Brasil - 2000, Mundo Estranho - 2001, Scientific American Brasil - 2002) e também com o aumento do número de trabalhos apresentados sobre o tema em eventos e periódicos no período entre 1997 e 2007, como apontado por Nascimento e Rezende Junior (2010). No ensino, podemos utilizar como marcos importantes na aproximação com a DC os Parâmetros Curriculares Nacionais para o Ensino Médio (PCNEM) e as Orientações Educacionais Complementares aos Parâmetros Curriculares Nacionais $(\mathrm{PCN}+)$, já que os $\mathrm{PCN}+$ trazem competências 
relacionadas à Representação e Comunicação (BRASIL, 2002) e os PCNEM trazem orientações a respeito da utilização da DC dentro de uma perspectiva do ensino contextualizado em que os(as) estudantes possam reconhecer os aspectos da ciência em sua realidade (BRASIL, 1999).

Dessa forma, podemos perceber que a divulgação científica cada vez mais se incorpora à nossa cultura, com isso aumentando também a importância de analisar criticamente essas informações e entender melhor o que é e para que serve a DC, ou ainda os termos popularização da ciência e vulgarização da ciência. É a forma pela qual o conhecimento científico é difundido visando o seu entendimento pelo público em geral, neste sentido os meios e espaços para que isso ocorra podem ser os mais diversos, por exemplo, os meios de comunicação, os livros, os museus e centros de ciências etc. (CUNHA, 2009).

Nesse contexto, pensando no aspecto de utilidade pública da DC, nos modos como a ciência se desenvolve e como as pessoas percebem a ciência, é importante que alguns cuidados sejam tomados na hora de fazer a divulgação desse conhecimento, pois se a boa divulgação científica tem a possibilidade de democratizar o acesso às informações que abrirão espaços para que as pessoas participem de forma mais crítica e consciente das tomadas de decisões a respeito da utilização dos conhecimentos e dos rumos do desenvolvimento científico (BUENO, 2010), a DC sem que se tome os cuidados necessários podem reforçar ideias que são negativas em um contexto de formação de cidadania, como de que a ciência é superior, que é autônoma e independente dos contextos políticos, sociais e culturais, de que apenas os grandes projetos e suas aplicações tecnológicas possuem valor (ALBAGLI, 1996).

Mediante o exposto, inferimos que a DC está presente no cotidiano das pessoas, ideia essa que é confirmada nos resultados da pesquisa sobre "Percepção Pública da Ciência e Tecnologia no Brasil" realizada nos anos de 1987, 2006, 2010, 2015 e 2019 por órgãos ligados ao Ministério da Ciência, Tecnologia e Inovações (MCTI), como o Centro de Gestão e Estudos Estratégicos (CGEE).

O MCTI tem como objetivo expandir as contribuições do órgão em relação a serviços públicos importantes para o desenvolvimento do país. O órgão caracteriza-se por três vertentes principais, a de produzir conhecimento; riquezas para o Brasil e contribuir para a qualidade de vida de brasileiros, possuindo como propósito garantir e 
promover o avanço da ciência, tecnologia, inovação e comunicação para a sociedade brasileira (BRASIL, 2019).

Já a pesquisa sobre a percepção pública no Brasil, realizada por esses órgãos, objetiva "conhecer a visão, o interesse e o grau de informação da população em relação à C\&T no País” (BRASIL, 2019, p. 7). Nesse sentido, busca-se, a partir dos dados, "aprimorar ações de popularização científica e de educação em ciências, assim como contribuir com a formulação de políticas públicas voltadas para essa temática" (BRASIL, 2019, p. 7).

Inicialmente, a pesquisa de percepção pública foi baseada em investigações já empregadas em outros países, como Estados Unidos e outros da Europa, e foi aplicada em 1987 no Brasil, no período de realização da Assembleia Nacional Constituinte, com a expectativa de que tais respostas fornecessem subsídios para novas ações do Conselho Nacional de Desenvolvimento Científico e Tecnológico (CNPq), promovessem a democratização do acesso às informações sobre a ciência produzida e também progresso do país. A pesquisa de 1987 compreendeu um universo de 2.892 entrevistas da população adulta residente nas áreas urbanas do país, com vários níveis socioeconômicos (BRASIL, 2017).

Em 2006, a pesquisa levou em consideração 7 questões usadas na aplicação, ocorrida no ano de 1987 para que fosse possível analisar tendências de percepção sobre a ciência e a tecnologia. Foram entrevistadas 2004 pessoas, de diversas regiões do país, com 16 anos ou mais. Para se manter uma série histórica, o mesmo foi feito em 2010 (com a participação de 2016 entrevistados), em 2015 (com 1962 participantes) e em 2019 com 2200 participantes, seguindo, geralmente, os mesmos critérios de idade, escolarização (todos os tipos), localidades dentro do país, para os entrevistados (BRASIL, 2017). Todas as pesquisas realizadas tinham basicamente o mesmo intuito: conhecer a percepção, o interesse e quanto as pessoas estão informadas sobre ciência e tecnologia no país.

Diante do exposto e dos resultados da pesquisa realizadas, sobre "Percepção Pública da Ciência e Tecnologia no Brasil", apresentadas durante os últimos anos (2006, 2010, 2015 e 2019), buscamos investigar: que relações existem entre as ideias ou percepções deste público participante da pesquisa sobre ciência e tecnologia (C\&T), a 
Edição Especial: I SSAPEC - Simpósio Sul-Americano de Pesquisa em Ensino de Ciências

ISSN: 2595- $4520 \quad$ Vol. 4, n. 3. 2021

imagem do (a) cientista e sobre suas próprias atitudes, durante os anos de aplicação da pesquisa?

Segundo Castelfranchi et al. (2013), as primeiras pesquisas realizadas, tanto em âmbito nacional, quanto internacional, mostraram o empobrecimento de conhecimentos acerca da ciência e do método científico. Já em investigações atuais, os autores apontam que quanto maior o acesso às informações, relacionadas às ciências e a tecnologia, mais divergentes são as opiniões sobre tais aspectos, pois as pessoas tornam-se mais criteriosas e costumam fazer análises, caso a caso, para exprimir suas opiniões, principalmente quando os temas envolvidos estão carregados de questões éticas como o uso dos transgênicos.

\section{METODOLOGIA}

Ao considerarmos que a DC está inserida na vida do público em geral, buscamos compreender algumas questões relacionadas à percepção pública do(a) brasileiro(a), visões sobre os(as) cientistas e seu papel, e suas atitudes diante da ciência. Inicialmente analisamos a totalidade de questões (41 questões) que tinham os resultados disponíveis no site do Ministério da Ciência, Tecnologia e Inovações (MCTI) e selecionamos as questões relacionadas, diretamente, às concepções de ciência como "A ciência e tecnologia trazem mais malefícios ou benefícios para a humanidade?" e "O desenvolvimento científico e tecnológico levará a uma diminuição das desigualdades sociais do país". Analisamos um total de 5 perguntas com relação ao modo como o brasileiro enxerga a ciência, escolhendo as questões que julgamos mais amplas e que possibilitasse um panorama sobre a percepção pública.

Também para entender como os entrevistados se relacionam com a ciência, buscamos selecionar as perguntas que se remetem à visão de cientista e seu papel na sociedade. Nesse âmbito foram selecionadas 5 questões, que indicam o modo como as pessoas pensam a ciência e o cientista e quão interessadas estão em conhecer seu funcionamento, dentre elas "Por causa do conhecimento, os(as) cientistas têm poderes que os tornam perigosos" e "É necessário que os(as) cientistas exponham publicamente os riscos decorrentes dos desenvolvimentos científicos e tecnológicos”. 
Edição Especial: I SSAPEC - Simpósio Sul-Americano de Pesquisa em Ensino de Ciências ISSN: 2595- $4520 \quad$ Vol. 4, n. 3. 2021

Além disso, utilizamos para análise as questões (3 para esse tópico) que faziam menção à relação do indivíduo respondente com a ciência, ou seja, como ele se percebe enquanto participante das decisões ou ainda entendedor da ciência que é desenvolvida. Com esse propósito, questões como "A população deve ser ouvida nas grandes decisões sobre os rumos da ciência e tecnologia" e "A maioria das pessoas é capaz de entender o conhecimento científico se ele for bem explicado", foram exploradas. Com isso, obtivemos uma totalidade de 13 questões analisadas neste trabalho.

Para o contexto da seleção e análise do material, utilizamos os preceitos da pesquisa qualitativa que se centra na compreensão e explicação das relações sociais. Esse método de pesquisa é usado quando se procura percepções e entendimento sobre o caráter geral de uma questão, dando espaço para a interpretação (GERHARDT, SILVEIRA, 2009). Para a análise dos dados, procuramos trazer reflexões acerca das três classes de questões selecionadas, a saber, a percepção da ciência, do(a) cientista e a relação do indivíduo respondente com a ciência.

\section{RESULTADOS E DISCUSSÕES}

Ao assumir uma postura crítica em relação à divulgação da ciência, é imprescindível que seja discutido, também, o próprio modo de produção da ciência, pois segundo Pechula, Gonçalves e Caldas (2013), o conhecimento científico e o desenvolvimento da ciência pode ser, geralmente, compreendido de duas maneiras: uma evidencia o conhecimento científico como único e universal, gerando resultados definitivos e absolutos, sustentado na visão de que a ciência é capaz de dissecar a natureza e traduzir para a linguagem matemática, enquanto a outra considera que humano, natureza, ciência e sociedade se relacionam de forma tal que é impossível haver separação.

Nesse sentido, a forma como se compreende o desenvolvimento da ciência reflete igualmente na percepção das pessoas de como a ciência pode contribuir, prejudicar, influenciar, e, consequentemente, na sua própria confiabilidade. Com isso, ao analisar os dados referentes à percepção pública sobre a ciência no Brasil, indicados no Quadro 01, observa-se que a maioria dos(as) brasileiros(as) acredita que a ciência e a tecnologia trazem mais benefícios que malefícios para a humanidade. 
Em torno de $75 \%$ dos entrevistados responderam que a ciência traz benefícios ou mais benefícios que malefícios, em todos os anos em que a pesquisa foi realizada. No entanto, outro fator importante a ser considerado é que o modo como as pessoas percebem a ciência está relacionado às atitudes que terão em relação ao conhecimento científico, nesse aspecto, Simon (2009) determina que quanto maior o consumo de informações a respeito da ciência através da mídia, mais cautelosas as pessoas se tornam em relação ao avanço científico, contrariando o modelo deficitário, onde o maior conhecimento conduziria a atitudes mais favoráveis.

Quadro 01: Percepção pública sobre ciência no Brasil.

\begin{tabular}{|c|c|c|c|c|c|}
\hline PERGUNTAS & 2006 & 2010 & 2015 & 2019 & \multirow[b]{2}{*}{ Legenda } \\
\hline \multirow{5}{*}{$\begin{array}{l}\text { A ciência e tecnologia trazem } \\
\text { mais malefícios ou benefícios } \\
\text { para a humanidade? }\end{array}$} & $8,33 \%$ & $1,60 \%$ & $11,13 \%$ & $5,04 \%$ & \\
\hline & $28,29 \%$ & $38,94 \%$ & $53,72 \%$ & $30,55 \%$ & \\
\hline & $45,66 \%$ & $42,30 \%$ & $19,10 \%$ & $41,55 \%$ & Benefícios \\
\hline & $13,17 \%$ & $13,99 \%$ & $11,82 \%$ & $18,86 \%$ & \\
\hline & $4,55 \%$ & $3,17 \%$ & $4,23 \%$ & $4,00 \%$ & que malefícios \\
\hline \multirow{5}{*}{$\begin{array}{l}\text { A ciência e a tecnologia vão } \\
\text { ajudar a eliminar a pobreza e a } \\
\text { fome do mundo? }\end{array}$} & $3,99 \%$ & $3,97 \%$ & $5,71 \%$ & $4,00 \%$ & \multirow{5}{*}{$\begin{array}{l}\text { Benefícios e } \\
\text { malefícios }\end{array}$} \\
\hline & $30,39 \%$ & $18,30 \%$ & $13,86 \%$ & $20,95 \%$ & \\
\hline & $27,00 \%$ & $14,43 \%$ & $30,99 \%$ & $37,55 \%$ & \\
\hline & $18,26 \%$ & $26,79 \%$ & $22,32 \%$ & $18,14 \%$ & \\
\hline & $20,36 \%$ & $36,51 \%$ & $27,12 \%$ & $19,36 \%$ & \\
\hline \multirow{5}{*}{$\begin{array}{l}\text { O desenvolvimento científico } \\
\text { e tecnológico levará a uma } \\
\text { diminuição das desigualdades } \\
\text { sociais do país? }\end{array}$} & $6,23 \%$ & $6,20 \%$ & $6,98 \%$ & $7,00 \%$ & \multirow{5}{*}{$\begin{array}{l}\text { Concordo } \\
\text { totalmente } \\
\text { Concordo } \\
\text { parcialmente }\end{array}$} \\
\hline & $25,70 \%$ & $29,51 \%$ & $17,23 \%$ & $18,91 \%$ & \\
\hline & $32,14 \%$ & $28,08 \%$ & $34,86 \%$ & $37,91 \%$ & \\
\hline & $16,27 \%$ & $14,14 \%$ & $20,59 \%$ & $21,45 \%$ & \\
\hline & $19,66 \%$ & $22,07 \%$ & $20,34 \%$ & $14,73 \%$ & \\
\hline \multirow{4}{*}{$\begin{array}{l}\text { A ciência e tecnologia são } \\
\text { responsáveis pela maior parte } \\
\text { dos problemas ambientais } \\
\text { atuais? }\end{array}$} & $4,94 \%$ & $2,78 \%$ & $5,91 \%$ & $5,13 \%$ & $\begin{array}{l}\text { Discordo } \\
\text { parcialmente }\end{array}$ \\
\hline & $58,94 \%$ & $68,95 \%$ & $21,92 \%$ & $18,36 \%$ & \multirow{8}{*}{$\begin{array}{l}\text { parcialmente } \\
\text { Discordo } \\
\text { totalmente }\end{array}$} \\
\hline & $22,55 \%$ & $16,91 \%$ & $34,56 \%$ & $39,14 \%$ & \\
\hline & $8,33 \%$ & $8,93 \%$ & $17,94 \%$ & $21,82 \%$ & \\
\hline \multirow{5}{*}{$\begin{array}{l}\text { Os governantes devem seguir } \\
\text { as orientações dos cientistas. }\end{array}$} & $\begin{array}{l}5,24 \% \\
529 \%\end{array}$ & $2,43 \%$ & $19,67 \%$ & $15,55 \%$ & \\
\hline & $34,43 \%$ & $37 \%$ & $18,09 \%$ & $21.36 \%$ & \\
\hline & $35,43 \%$ & $33,58 \%$ & $41,28 \%$ & $44,68 \%$ & \\
\hline & $14,62 \%$ & $13 \%$ & $15,95 \%$ & $17,78 \%$ & \\
\hline & $10,23 \%$ & $10,91 \%$ & $17,79 \%$ & $10,95 \%$ & \\
\hline
\end{tabular}

Fonte: Extraído e adaptado de Brasil (2019).

Desse modo, apesar de a maioria responder que trazem mais benefícios, metade das que responderam as pesquisas nos anos de 2006, 2010, 2015 e 2019, como indicado no Quadro 01, concordam totalmente ou parcialmente com as afirmações de que a ciência e a tecnologia podem contribuir com questões sociais importantes como a Recebido em: 18/01/2021

Aceito em: 24/02/2021 
Edição Especial: I SSAPEC - Simpósio Sul-Americano de Pesquisa em Ensino de Ciências ISSN: 2595- $4520 \quad$ Vol. 4, n. 3. 2021

eliminação da pobreza e a fome do mundo e a diminuição das desigualdades sociais, demonstrando que uma parte considerável da população não confia na ciência e na tecnologia para solucionar ou minimizar tais problemas.

Outro aspecto importante, no que diz respeito à percepção pública da ciência e da tecnologia, e que demonstra uma visão mais negativa, está relacionado ao questionamento se a ciência e tecnologia são responsáveis pela maior parte dos problemas ambientais atuais. Nesse contexto, aproximadamente $70 \%$ dos entrevistados concordaram totalmente ou parcialmente com a afirmação, apesar dos dados mostrarem que essa percepção tem diminuído nos últimos anos (2015 e 2019).

Também é interessante notar que, apesar do resultado aumentar em relação à pesquisa de 2015, mas ainda continuar abaixo dos valores de 2006 e 2010, aproximadamente $66 \%$ das pessoas concordam parcial ou totalmente que os governantes devem seguir as orientações dos(as) cientistas, diante de cerca de 34\% que discordam parcial ou totalmente ou não sabem responder. Esse dado se mostra contrastante com os $72 \%$ que responderam acreditar que a ciência traz apenas benefícios ou mais benefícios do que malefícios, ou seja, mesmo entre aquelas pessoas que acreditam nos benefícios da ciência, há quem afirme que os governantes não devem seguir as orientações dos(as) cientistas.

Nessa perspectiva, vale considerar a importância da DC, para que a ciência seja compreendida como uma prática social, portanto, resultado de um processo histórico e cultural que não é independente do sujeito e das ideologias. No entanto, quando o conhecimento passa da esfera científica para a esfera midiática, no discurso haverá as percepções e concepções da pessoa que divulga (CUNHA, 2009). Assim, são necessários alguns cuidados, pois a divulgação científica está relacionada também à percepção pública da ciência e pode ter efeitos outros que não os de colaborar no intuito de democratizar e problematizar o conhecimento, estabelecendo uma cultura científica voltada para o exercício da cidadania.

Nesse âmbito, a imagem difundida sobre a ciência, o(a) cientista e seu papel, geralmente os marcam distantes do contexto social. Segundo Zanon e Machado (2013, p. 47), "nota-se que as concepções de ciências e de cientista amplamente difundidas pelos meios de comunicação constroem uma visão deformada e divulgam o trabalho e as atividades científicas resumidas somente à experimentação e às grandes descobertas". 
Essa pode reforçar concepções contraditórias acerca da complexidade da ciência e do papel do(a) cientista, frente aos problemas socialmente postos.

Neste sentido, buscamos explorar a percepção pública sobre a imagem do(a) cientista que a população brasileira possui, pois, a associação da imagem do(a) cientista bem como a atividade científica a algo de cunho extraordinário é comumente discutida e observada em nossa sociedade, a isto está relacionado ao trabalho realizado por ele, uma vez que a percepção do(a) cientista é uma representação composta por sua apresentação física e de seu comportamento social, profissional e pessoal.

Em relação à imagem dos(as) cientistas (Quadro 02), uma das percepções que mais chamam a atenção é a afirmação em que, em 2019, cerca de $65 \%$ das pessoas concordam que "por causa do conhecimento, os(as) cientistas têm poderes que os(as) tornam perigosos(as)".

Quadro 02: Percepção pública sobre o(a) cientista e seu papel na sociedade.

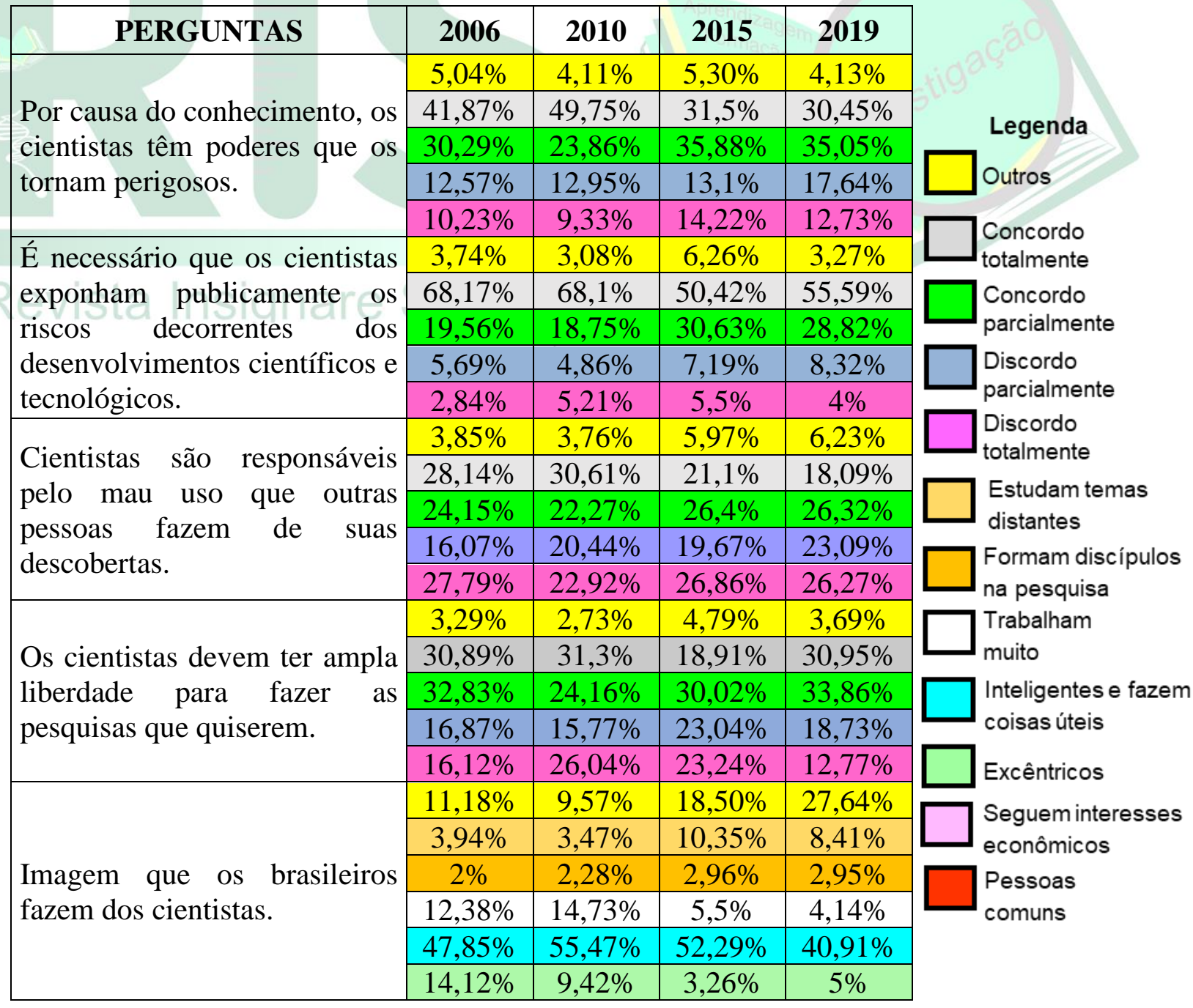

Recebido em: 18/01/2021

Aceito em: 24/02/2021 


\begin{tabular}{|c|c|c|c|}
\hline $8,53 \%$ & $5,06 \%$ & $7,14 \%$ & $10,95 \%$ \\
\hline $7,29 \%$ & $7,69 \%$ & $12,74 \%$ & $22,73 \%$ \\
\hline
\end{tabular}

Fonte: Extraído e adaptado de Brasil (2019).

Em um primeiro momento, essa informação pode parecer muito destoante da visão positiva dos, aproximadamente, $70 \%$ que afirmaram que a ciência traz "só benefícios" ou "mais benefícios que malefícios", no entanto, essa percepção positiva não se consolida quando questionadas sobre aspectos específicos, tais quais a responsabilidade pelos problemas ambientais, a eliminação da fome e da pobreza ou a diminuição das desigualdades sociais no país, nesses aspectos, sobretudo em relação aos problemas ambientais, há uma percepção mais negativa da ciência e da tecnologia.

É interessante notar, no entanto, que ao longo dos anos a visão da população brasileira sobre os(as) cientistas vem mudando, a cada edição da pesquisa, pois menos pessoas dizem concordar totalmente com a afirmação de que o conhecimento científico, de alguma forma, torna essas pessoas perigosas, mas ainda se mostram bastante reticentes à ciência e o número de pessoas que concordam parcialmente com essa ideia tem aumentado. Essa situação parece acompanhar, também, a percepção sobre a ciência. Enquanto a visão positiva - que só há benefícios - vem em uma tendência de diminuição, o aspecto crítico - que considera os benefícios, mas também os malefícios vem em uma tendência de aumento.

Outro ponto relevante sobre o(a) cientista e sua relação com a sociedade é a diminuição do percentual de pessoas que concordam totalmente com a afirmação de que "é necessário que os(as) cientistas exponham publicamente os riscos decorrentes dos desenvolvimentos científicos e tecnológicos”. Os dados de 2019 nos mostram algumas informações relevantes sobre a percepção que os(as) brasileiros(as) têm da sua relação com a ciência, apesar de próximas, a quantidade de pessoas que se declaram interessadas ou muito interessadas por ciência e tecnologia e a quantidade de pessoas que concordam totalmente com a afirmação, respectivamente, $61 \%$ e 55,59\%, revelam que a maior parte das pessoas que se declaram interessadas ou muito interessadas por ciência e tecnologia querem estar informadas também dos riscos envolvidos, mas uma parcela significativa dessas pessoas, e uma parcela ainda maior da população, tem ressalvas ao conhecimento públicos dos riscos do desenvolvimento científico e tecnológico. 
Edição Especial: I SSAPEC - Simpósio Sul-Americano de Pesquisa em Ensino de Ciências ISSN: 2595- $4520 \quad$ Vol. 4, n. 3. 2021

Santos (2007) discute a importância do letramento científico e tecnológico trazendo como função social deste questionar os modelos e valores do desenvolvimento científico e tecnológico na nossa sociedade. Abordando, também, a importância de não restringir as tomadas de decisões aos tecnocratas, mas, ao contrário, que as pessoas participem das decisões democráticas e questionem a ideologia dominante do desenvolvimento tecnológico. Os resultados da pesquisa nos indicam ainda um longo caminho para que tenhamos uma sociedade que assume como sua responsabilidade as discussões e as decisões sobre os rumos da ciência e tecnologia que afetam a todas as pessoas, individual ou coletivamente.

Ainda no aspecto da atividade científica, um ponto importante a ser analisado é o que tem relação com a liberdade de pesquisa, no qual as pesquisas apontam que cada vez menos discordam totalmente da afirmação "os(as) cientistas devem ter ampla liberdade para fazer as pesquisas que quiserem", o que demonstra uma certa confiança na ciência, representando assim, um certo reflexo de como as pessoas veem a ciência. Ao comparar esses dados com a afirmação a respeito dos benefícios e malefícios da ciência, teremos, para a edição de 2019 da pesquisa, valores muito parecidos, com grandes variações apenas no que diz respeito à quantidade de pessoas que acreditam que a ciência causa mais malefícios ou apenas malefícios, 4\%, e que acreditam que de nenhum modo deve haver ampla liberdade de pesquisa, 12,77\%. Dessa forma, podemos perceber que um número considerável de pessoas que dizem confiar nos benefícios da ciência, embora não confiem suficientemente nas pessoas que a fazem para decidir sobre o que devem pesquisar, o que pode ter relação com uma visão utilitarista da ciência.

A imagem que os(as) brasileiros(as) fazem dos(as) cientistas e, principalmente, a mudança dessa imagem ao longo dos anos nos dá pistas para tentar compreender algumas coisas, por exemplo, apesar de estar diminuindo ao longo das pesquisas, a visão predominante é, justamente, a utilitarista, cerca de $40 \%$ das pessoas veem o(a) cientista como pessoas que são "inteligentes e fazem coisas úteis", isso tende a corroborar com a visão de que os objetos de pesquisa devem ser controlados, o que pode implicar também na discordância total ou parcial em relação à ampla liberdade de pesquisa. O que encontra relação com a discussão proposta por Souza (2011, p. 224), no qual expõe que: 
A ampliação do acesso à informação através de novas tecnologias não vem significando aumento do capital cultural da classe trabalhadora. A massa informacional aumentou, mas a natureza da informação que tem chegado às nossas escolas tem gerado conhecimentos esvaziados de suas bases teóricas, reduzidos à sua dimensão utilitária, o que vem causando uma alienação de novo tipo: a alienação informacional, que gera a desinformação.

Uma visão que vem aumentando ao longo dos anos é a de que cientistas são “pessoas comuns com treinamento especial”, sendo a visão de, aproximadamente, $22 \%$ das pessoas entrevistadas, o que vai de encontro com a queda, ao longo dos anos, da quantidade de pessoas que concordam totalmente que "por causa do conhecimento, os(as) cientistas têm poderes que os(as) tornam perigosos(as)". Sobre esse aspecto é interessante analisar a mudança da imagem dos(as) cientistas nos filmes, sendo possível que haja uma relação. Enquanto anteriormente dominava uma representação estereotipada com características negativas (como o químico mau, louco, perigoso ou o nerd e excêntrico), mais recentemente há uma diversificação maior no que diz respeito tanto às áreas de atuação quanto ao comportamento, com destaque para características positivas (cientistas inventores, inteligentes, atrapalhados e midiáticos) (REZNIK, MASSARANI, MOREIRA; 2019).

Outra visão que aparece menos que as anteriormente citadas, mas também bastante relevante, é a de que são "pessoas que servem a interesses econômicos e produzem conhecimentos em áreas nem sempre desejáveis", por volta de $11 \%$, e representa uma visão mais crítica em relação à produção do conhecimento. A esse respeito Souza (2010), traz uma importante reflexão, pois as contradições do capitalismo não excetuam a ciência e nem a tecnologia, que não são neutras, mas, ao serem tratadas dessa forma, legitima uma relação de domínio e exploração da natureza.

Há ainda algumas visões menos comuns, como a de "pessoas que trabalham muito sem querer ficar ricas", em torno de 4\%, e "pessoas que formam discípulos na sua área de pesquisa", próximo de $3 \%$, que são visões mais voltadas para a dedicação ao trabalho. No entanto, há também visões como a de que cientistas são "pessoas que se interessam por temas distantes das realidades das pessoas", com pouco mais de $8 \%$, e, ainda, "pessoas excêntricas de fala complicada", 5\%, que evidenciam fortemente o desinteresse de uma parcela da população pela ciência, sobretudo, pelo fato de a soma desses percentuais ser, exatamente, o percentual de pessoas que se declararam nada interessadas por ciência e tecnologia. 
Quanto às questões sobre a percepção pública e o interesse sobre a C\&T no Brasil nos anos de 2006, 2010, 2015 e 2019, por volta de 40\% mostraram-se pouco interessados ou nada interessados, como indicado no Quadro 03. No entanto, quando questionados sobre ouvir a população nas decisões sobre os rumos da ciência e tecnologia, acima de $80 \%$, das pessoas respondentes na série histórica, concordam total ou parcialmente que a população deve ter voz nessas questões. Esses dados demonstram contradições acerca do baixo interesse com relação à ciência, mas ao mesmo tempo querem participar de decisões relativas aos assuntos que não necessariamente compreendem ou tem interesse.

Quadro 03: Relação do indivíduo respondente com a ciência no Brasil.

\begin{tabular}{|c|c|c|c|c|c|}
\hline PERGUNTAS & 2006 & 2010 & 2015 & 2019 & \multirow[b]{2}{*}{ Legenda } \\
\hline \multirow{5}{*}{$\begin{array}{l}\text { Interesse do brasileiro por } \\
\text { Ciência e Tecnologia }\end{array}$} & $1,30 \%$ & $0,40 \%$ & $0,71 \%$ & $1,09 \%$ & \\
\hline & - & $34,92 \%$ & $35,02 \%$ & $37,09 \%$ & \multirow{4}{*}{$\begin{array}{l}\text { Interessado } \\
\text { Muito interessado } \\
\text { Pouco interessado }\end{array}$} \\
\hline & $40,72 \%$ & $29,91 \%$ & $25,94 \%$ & $23,91 \%$ & \\
\hline & $34,68 \%$ & $19,59 \%$ & $25,43 \%$ & $24,50 \%$ & \\
\hline & $23,30 \%$ & $15,18 \%$ & $12,90 \%$ & $13,41 \%$ & \\
\hline \multirow{5}{*}{$\begin{array}{l}\text { A população deve ser ouvida } \\
\text { nas grandes decisões sobre os } \\
\text { rumos da ciência e tecnologia }\end{array}$} & $2,99 \%$ & $1,19 \%$ & $4,49 \%$ & $2,73 \%$ & \multirow[b]{2}{*}{ Nada interessado } \\
\hline & $62,78 \%$ & $66,36 \%$ & $46,89 \%$ & $52,81 \%$ & \\
\hline & $26,05 \%$ & $22,87 \%$ & $36,80 \%$ & $30,55 \%$ & \multirow{3}{*}{$\begin{array}{l}\text { Outros } \\
\text { Concordo } \\
\text { totalmente }\end{array}$} \\
\hline & $4,94 \%$ & $5,36 \%$ & $6,01 \%$ & $8,59 \%$ & \\
\hline & $3,24 \%$ & $4,22 \%$ & $5,81 \%$ & $5,32 \%$ & \\
\hline \multirow{5}{*}{$\begin{array}{l}\text { A maioria das pessoas é capaz } \\
\text { de entender o conhecimento } \\
\text { científico se ele for bem } \\
\text { explicado }\end{array}$} & $2,55 \%$ & $1,79 \%$ & $3,92 \%$ & $2,23 \%$ & \multirow{5}{*}{$\begin{array}{l}\text { Concordo } \\
\text { parcialmente } \\
\text { Discordo } \\
\text { parcialmente } \\
\text { Discordo } \\
\text { totalmente }\end{array}$} \\
\hline & $52,29 \%$ & $56,00 \%$ & $43,73 \%$ & $49,91 \%$ & \\
\hline & $29,39 \%$ & $25,25 \%$ & $31,60 \%$ & $32,27 \%$ & \\
\hline & $10,18 \%$ & $8,28 \%$ & $10,40 \%$ & $9,82 \%$ & \\
\hline & $5,59 \%$ & $8,68 \%$ & $10,35 \%$ & $5,77 \%$ & \\
\hline
\end{tabular}

Fonte: Extraído e adaptado de Brasil (2019).

A falta de interesse, combinada à ideia de quem nem todas as pessoas podem ou conseguem aprender ciências, mas ainda acreditando que, devem ser ouvidas nas decisões acerca dos rumos da ciência e da tecnologia, podem favorecer que as pessoas se informem e propaguem informações por meio de veículos inadequados e questionáveis. Santos e Vieira Junior (2019, p. 2), discutem que "com o advento das redes sociais, a divulgação das notícias falsas, ou fake news, em inglês, tomaram proporções incontroláveis em todo o mundo". 
De maneira semelhante, ao longo das edições da pesquisa, parte dos entrevistados concorda que a maioria das pessoas é capaz de entender o conhecimento científico se ele for bem explicado. No entanto, a atenção está no fato que, historicamente, cerca de $50 \%$ das pessoas têm dúvidas ou acreditam que o conhecimento científico não pode ser compreendido por todas as pessoas.

Pelo fato de parte das pessoas não terem interesse, acesso e ainda dificuldade na compreensão dos conceitos envolvidos, dificilmente possuem criticidade para avaliar as informações, quanto a coerência, o conteúdo, a validade e a pertinência da informação. Com isso, Henriques (2018, p. 10) afirma que

[...] as informações equivocadas podem levar a diversos comportamentos e atitudes geradoras de risco, seja pela indução ao uso de tecnologias inadequadas, como medicamentos e vacinas sem indicação, ou, no outro extremo, pela recusa a tecnologias e medidas de proteção necessárias ou ainda pela desorganização que provocam nos serviços, de saúde.

No contexto da divulgação de fake news, Gomes, Penna e Arroio (2020) discutem sobre a necessidade de letramento científico e informacional e que, por meio desses, é possível combater tais informações e tornar as pessoas mais comprometidas com fatos. Nesse âmbito, a importância em se aprender ciência, para além dos conceitos, com vistas a formação crítica, ao questionamento e ao rompimento com ideias de senso comum, que quando não problematizadas podem constituir-se como parte do conhecimento de cada indivíduo.

Neste sentido, as concepções que possuímos sobre a ciência ou sobre a imagem do(a) cientista, surgem por meio de um processo primeiramente e principalmente, individual, no qual a partir do social o mesmo pode ser construído e modificado, produzindo o que se chama de conceitos (PONTE, 1992). De acordo com o mesmo autor "as concepções formam-se num processo simultaneamente individual (como resultado da elaboração sobre a nossa experiência) e social (como resultado do confronto das nossas elaborações com as dos outros) [...]" (PONTE, 1992, p.1). Ainda, as concepções são processos cognitivos, sendo tratadas como,

[...] indispensáveis pois estruturam o sentido que damos às coisas. Por outro lado, actuam como elemento bloqueador em relação a novas realidades ou a certos problemas, limitando as nossas possibilidades de actuação e compreensão (PONTE, 1992, p. 1). 
Nessa mesma perspectiva, para Vigotski (1991), as concepções fazem parte de um processo contínuo de aprendizagem, que não se encontra intacto. Porém, não existe uma definição exata sobre o assunto. Para Cunha (2009, p.49) a concepção seria o entendimento de uma situação, na qual, “[...] somente após o processo de significação e formação conceitual estaríamos aptos a conceber algo ou alguma coisa - ter uma concepção do objeto e condições de resolver um problema”.

No entanto, o desconhecimento da ciência pode afastar o interesse dos indivíduos sobre temas que envolvem os(as) cientistas, enquanto que para Kominsky e Giordan (2002, p.11) as concepções "também devem ser influenciadas pelo pensamento científico e pelas expressões de sua cultura, cujos traços são parcialmente divulgados na mídia”. Para minimizar este distanciamento da ciência que a sociedade muitas vezes possui, existem meios de DC (livros, filmes, revistas, desenhos animados) que quando discutidos e utilizados de forma crítica auxiliam positivamente a promover o interesse da sociedade pela ciência.

\section{CONSIDERAÇÕES FINAIS}

Castelfranchi et al. (2013) discutem que existe a tendência em grupos com maior formação ou informação serem mais criteriosos e críticos em respeito a algumas questões da ciência e tecnologia, tendência que contraria a ideia de que menos formação ou informação levam a uma percepção mais pessimista da ciência.

Apesar disso, quando refletimos sobre os dados das pesquisas sobre a percepção pública do(a) brasileiro(a), ao mesmo tempo em que se mostram confiantes nos benefícios da ciência e da tecnologia, não se mostram tão confiantes em relação a quais benefícios poderiam ser trazidos pelo desenvolvimento da ciência e da tecnologia, uma vez que não apresentam o mesmo grau de confiança em relação à ciência ajudar a solucionar problemas como fome e pobreza e considerá-la como uma das maiores responsáveis pelos problemas ambientais. Do mesmo modo, os dados se mostraram contrastantes quanto à importância da participação em decisões sobre o rumo da ciência, mas boa parcela se mostra pouco interessado por ciência ou ainda acredita que uma parte das pessoas não é capaz de aprender ciência. 
A imagem que as pessoas fazem do(a) cientista pode nos fornecer dados importantes para entender como se relacionam com a ciência. A visão caricata de cientistas pode ser um dos motivos pelos quais as pessoas não se interessam pela ciência e, também, pode estar entre as causas de graves distorções da atividade científica. É preocupante a quantidade de pessoas que acreditam que o conhecimento científico torna pessoas perigosas.

Destarte, a importância em se utilizar formas de entender a ciência e sua configuração de desenvolvimento, o que pode ser favorecido pelo uso de materiais de divulgação da ciência. Nesse contexto, a ciência pode ser problematizada de modo a entender o seu papel na sociedade, minimizando concepções contraditórias acerca "do bem e do mal" produzido por ela, bem como, que tal conhecimento tem de ser estudado, compreendido e acessível para todos.

A discussão proposta por Albagli (1996) mostra-se ainda atual em seus questionamentos sobre quais os objetivos e os resultados da divulgação científica que vem sendo feita. Com o panorama proporcionado pelas pesquisas sobre a Percepção Pública da Ciência e da Tecnologia no Brasil, ainda que possamos perceber alguns avanços, ainda há muito a ser feito e a ser compreendido para que, efetivamente, as pessoas possam compreender a ciência e a tecnologia e tomar parte no que elas fazem e no que delas resulta.

\section{REFERÊNCIAS}

ALBAGLI, S. Divulgação científica: informação científica para a cidadania? Ciência da Informação, v. 25, n. 3, p. 396-404, 1996.

BRASIL, Parâmetros Curriculares Nacionais: Ensino Médio - Ciências da Natureza, Matemática e suas Tecnologias. Brasília: MEC/SEF, 1999.

BRASIL. Orientações Complementares aos Parâmetros Curriculares Nacionais: Ciências da Natureza, Matemática e suas Tecnologias. Brasília: MEC/SEF, 2002.

BRASIL. Ministério da Ciência, Tecnologia, Inovações (MCTI). Percepção pública da C\&T no Brasil: 2015. Brasília, DF: Centro de Gestão e Estudos Estratégicos, 2017.

BRASIL. Ministério da Ciência, Tecnologia, Inovações (MCTI). Percepção pública da C\&T no Brasil - 2019 - Resumo executivo. Brasília: Centro de Gestão e Estudos Estratégicos, 2019.

BUENO, W. C. Comunicação científica e divulgação científica: aproximações e rupturas conceituais. Informação \& Informação, v. 15, n. esp, p. 1-12, 2010. 
CASTELFRANCHI, Y; VILELA, E. M.; LIMA, L. B.; MOREIRA, I. C.;

MASSARANI, L. As opiniões dos brasileiros sobre ciência e tecnologia: o 'paradoxo' da relação entre informação e atitudes. História, Ciências, Saúde, v. 20, p. 1163-1183, 2013.

CUNHA, M. B. A percepção de ciência e tecnologia por estudantes de ensino médio e a divulgação científica. Tese (Doutorado em Ensino de Ciências e Matemática) Faculdade de Educação, Universidade de São Paulo, São Paulo, 2009.

GERHARDT, T. E.; SILVEIRA, D. T. Métodos de pesquisa. Porto Alegre: Editora da UFRGS, 2009.

GOMES, S. F.; PENNA, J. C. B. O.; ARROIO, A. Fake News Científicas: Percepção, Persuasão e Letramento. Ciência \& Educação, v. 26, e. 20018, 2020.

HENRIQUES, C. M. P. A dupla epidemia: febre amarela e desinformação. Revista Eletrônica de Comunicação, Informação e Inovação em Saúde, v. 12, n. 1, jan./mar., 2018.

KOSMINSKY, L.; GIORDAN, M. Visões de ciência e sobre o cientista entre estudantes do ensino médio. Química Nova na Escola, vol. 15, nº. 15, p. 11-18, 2002. Disponível em: <http://qnesc.sbq.org.br/online/qnesc15/v15a03.pdf>. Acesso: 15 de jan. de 2021.

NASCIMENTO, T. G.; REZENDE JUNIOR, M. K. A produção sobre divulgação científica na área de educação em ciências: referenciais teóricos e principais temáticas. Investigações em Ensino de Ciências, v. 15, n.1, p. 97-120, 2010.

PECHULA, M. R.; GONÇALVES, E.; CALDAS, G. Divulgação científica: discurso, mídia e educação. Controvérsias e perspectivas. Redes.Com, n. 7, p. 43-60, 2013.

PONTE, J. P. da. Concepções dos Professores de Matemática e Processos de Formação. Editora Instituto de Inovação Educacional, 1992. Disponível em: <http://hdl.handle.net/10451/2985>. Acesso: 15 de jan. de 2021.

REZNIK, G.; MASSARANI, L.; MOREIRA, I. de C. Como a imagem de cientista aparece em curtas de animação? Hist. cienc. saúde-Manguinhos, v. 26, n. 3, p. 753777, 2019. Disponível em: <http://www.scielo.br/scielo.php?script=sci_arttext\&pid=S010459702019000300753\&lng=en\&nrm=iso>. acesso em 14 Jan. 2021.

SANTOS, W. L. P. dos. Educação científica na perspectiva de letramento como prática social: funções, princípios e desafios. Rev. Bras. Educ., v. 12, n. 36, p. 474-492, 2007. Disponível em: <http://www.scielo.br/scielo.php?script=sci_arttext\&pid=S1413$24782007000300007 \& \operatorname{lng}=$ en\&nrm=iso $>$. acesso em 15 Jan. 2021.

SANTOS, M. J.; VIEIRA JÚNIOR, N. Repercussões das fake news na educação em ciências: estímulo ao pensamento crítico e reflexivo no ensino fundamental II. Revista Brasileira de Educação Básica, v. 4, n. 13, abril/junho, 2019.

SIMON, F. O. Percepção de ciência: relações entre conhecimentos, crenças e atitudes e fatores sócio-demográficos. Tese (Doutorado em Educação) - Faculdade de Educação, Universidade Estadual de Campinas, Campinas, 2009.

SOUZA, E. G. Sociedade da informação e reestruturação produtiva: crítica à dimensão utilitarista do conhecimento. Transinformação, v. 23, n. 3, p. 219-226, 2011. 
Edição Especial: I SSAPEC - Simpósio Sul-Americano de Pesquisa em Ensino de Ciências

Disponível em: <http://www.scielo.br/scielo.php?script=sci_arttext\&pid=S0103$37862011000300004 \& \operatorname{lng}=e n \& n r m=i s o>$. acesso em 15 jan. 2021.

SOUZA, J. P. M. de. Ciência e capitalismo. Filosofia e Educação, v. 2, n. 2, p. 266280, 2010. Disponível em:

https://periodicos.sbu.unicamp.br/ojs/index.php/rfe/article/view/8635504. Acesso em: 16 jan. 2021.

VYGOTSKY, L. S. A formação social da mente: o desenvolvimento dos processos psicológicos superiores. $4^{\mathrm{a}}$ ed. São Paulo: Martins Fontes, 1991.

ZANON, A. V.; MACHADO, A, T. A visão do cotidiano de um cientista retratada por estudantes iniciantes de licenciatura em química. Ciência e Cognição, v. 18, 2013. 